\title{
Preventable Irregularity in Phenytoin (PHT) Plasma Levels in a Psychiatric Patient with Co-morbid Seizure Disorder
}

\author{
Walid Aziz, Suneeta Kumari, Mansoor Malik and Partam Manalai* \\ Howard University Hospital, Psychiatry and Behavioral Sciences, United States
}

Submission: November 28, 2017; Published: December 06, 2017

*Corresponding author: Partam Manalai, M.D.Howard University Hospital, Department of Psychiatry and Behavioral Sciences, 2041 Georgia Avenue, NW Suite 5B01, Washington, D.C. 20060, United States; Email: partam.manalai@howard.edu

\begin{abstract}
Epilepsy is the most common chronic disorder of the central nervous system affecting between 40 and 100 million people worldwide [1]. Furthermore, co-morbid psychiatric disorders appear to be more common in patients with epilepsy than within the general population. Gaitatzis et al. [2] reported that up to $6 \%$ of epileptic patients had co-morbid psychiatric conditions in patients suffering from temporal lobe epilepsy whether refractory cases or not, the rate of psychiatric co morbidity is even higher at 10-20\%. Phenytoin (PHT) is a well-known therapy as an initial or adjunctive treatment of focal and generalized seizures, excluding absence and myoclonic seizures [3]. Unfortunately, the unusual pharmacokinetics of PHT along with polypharmacyexpose patients to undesirable adverse effects [4]. As such, these patients pose a management challenge, mainly when treated with (PHT) in addition to other drugs which lead to drug-drug interaction [5]. Here, we describe a case of PHT toxicity followed by sub-therapeutic levels of the drug in a psychiatric patient. We will also review the pharmacokinetics of PHT, drug-drug interaction dosing recommendations.
\end{abstract}

Keywords: Case; Report; Phenytoin; Seizure; Psychiatry; Howard; Hospital

Abbreviations: PHT: Phenytoin; EEG: Electro Encephalo Gram; CBC: Complete Blood Count; CMP: Comprehensive Metabolic Panel; LFT: Liver Function Test; TFT: Thyroid Function Test; HIV: Human Immunodeficiency Virus; RPR: Rapid Plasma Reagin; HBV: Hepatitis B Virus ; HCV: Hepatitis C Virus; INH: Isoniazid; CYP: CytochromeP450; PMDD: Premenstrual Dysphoric Disorder

\section{Case Report}

Ms. Gwas a 45-year-old single Caucasian female who was admitted to a public psychiatric facility due to agitation aggression and suicidal ideation toward a roommate when her roommate refused to do the chores/ clean the dishes. Police brought the patient from a community group home where she was staying for past six years. At the time of admission, the patient was agitated, uncooperative, and guarded. She endorsed suicidal ideation "I want to kill my roommate" with a plan. She was treated with Ativan- Benadryl- Haldol cocktail. On the 2nd day of admission patient Ms. G was pursuable, cooperative and receptive- she agreed to provide additional information. When she was inquired about past medical history, the patient reported a history of seizure disorder since age nine, and at age ten she developed affective and psychoticsymptoms. Also, after her father's death, she begins to experience suicidal ideation and behavior- she reported numerous suicide attempts; including drug overdose and cutting her wrist due to unspecific triggers.
Ms.G has an extensive history of hospitalizations throughout her childhood and adult life due to her previous symptoms, which later, during the hospital stay, was diagnosed with schizoaffective disorder. An MRI of the head done in earlier hospitalizations discovered an incidental paramedian falcine meningioma. It was later determined to be of no clinical significance since it remained unchanged with repeated imaging studies over the years. Neuropsychological testing revealed dyslexia and below average intellectual functioning. Three years ago, a continuous 24-hour video electroencephalogram (EEG) of the patient showed both epileptic and non-epileptic events; out of 19 push-button events, only two events were significant with subtle right-sided slowing. During these two events, the patient was uncomfortable, fidgets and had a generalized tonic-clonic seizure lasted 90-120 seconds.

Her current hospitalization has thus far spanned 13 months at the public psychiatric facility. On this current admission, 
the patient had an extensive laboratory workup, including Complete Blood Count (CBC), Comprehensive Metabolic Panel (CMP) Liver Function Test (LFT), Thyroid Function Test (TFT), blood chemistry, electrolytes, folic acid, and B12 levels, the results of which were within reasonable limits. The patient was seronegative for Human Immunodeficiency Virus (HIV), Rapid Plasma Reagin (RPR), Hepatitis B Virus (HBV), and Hepatitis C Virus (HCV). Her diagnosis was determined to be Schizoaffective Disorder Depressive type (295.70), Premenstrual Dysphoric Disorder (625.4), Other specified Impulse Control Disorder (312.89), Major Neurocognitive Disorder Due to Another Medical Condition (294.11), Specific Learning Disorder With impairments in mathematics (315.1), and Intellectual Disability Moderate (318.0). Borderline Personality Disorder (301.83) was considered a rule-out diagnosis. Also, the patient had complex partial seizure disorder with secondary generalization along with a right paramedian falcine meningioma. Unemployment, lack of housing, and lack of a primary support group.

Though the patient had a previous medication regimen at her group home, the complexity of her symptoms advocated that she was initially treated with clonazepam (Klonopin) 3mg PO QID and 2mg PO QHS, diphenhydramine hydrochloride (Benadryl) $50 \mathrm{mg}$ PO TID, and PHT 300mg PO BID. For the first six months of her current hospitalization, the patient remained seizurefree. The patient, however, continued to complain of insomnia for which eszopiclone2mg QHS was prescribed. She appeared to be responding well to treatment, except for preceding her menstrual periods, during which time she would show signs of agitation, pacing about the ward, and insomnia. On occasion, this phenomenon was followed by a seizure. The patient reported her mood symptoms get worse before the initiation of menstrual cycle a condition she was diagnosed previously known as Premenstrual Dysphoric Disorder (PMDD).

Norethindrone/Ethinyl estradiol (Ortho-Novum) 1mg PO once daily was added to her drug regimen to manage the PMDD. Soon after adding the oral contraceptive, her plasma PHT level increased to $37.8 \mathrm{mcg} / \mathrm{mL}$, much higher than the therapeutic range of $10-20 \mathrm{mcg} / \mathrm{mL}$ [6]. Overall, the oral contraceptive did not alleviate her PMDD. Therefore, this medication was discontinued, and the PHT was stopped immediately for a 4-day period and then restarted at $200 \mathrm{mg} P O$ once daily (rather than the previous $300 \mathrm{mg}$ PO BID). Subsequently, the patient experienced a complex partial seizure. The patient's PHT levels dropped to $8.1 \mathrm{mcg} / \mathrm{mL}$. Neurology consultation was obtained, and the PHT dosage was re-adjusted over time to Phenytoin 200mg QAM and 250mg QHS. During hospitalization, the patient developed symptoms of pulmonary TB. A routine diagnostic test revealed the patient's PPD test as positive; the same test had been negative only one year ago. Subsequent diagnostics such as chest X-ray and CT scan showed old pulmonary infiltrates in the left lower lobe of the lung with no hilar or mediastinal lymphadenopathy. Isoniazid (INH) was initiated at $300 \mathrm{mg}$ PO once daily along with pyridoxine $50 \mathrm{mg}$ PO once daily without adjusting the dosage of PHT. Not surprisingly, PHT levels spiked to 24.9 from therapeutic range; at which time the patient began showing signs of PHT toxicity. Neurology consultation was requested again, the PHT dosage was adjusted, and levels fell back into the normal range. PHT level remained within therapeutic range. Concurrently, the patient's insomnia persisted, so zolpidem tartrate (Ambien) $6.25 \mathrm{mg}$ PO QHS was introduced.

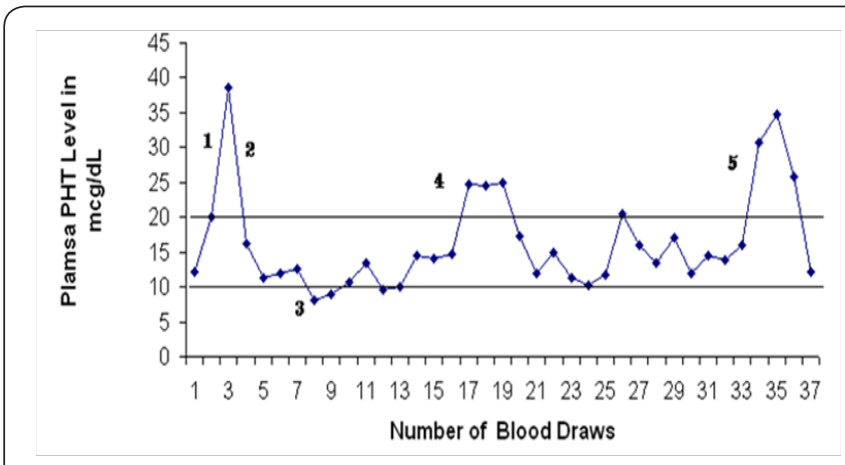

Figure 1: Graphic presentation of variations in patient's plasma PHT level over nine months stays at the hospital.

Note: Patients plasma phenytoin levels over 9 month period.

The patient's PMDD symptoms persisted; these episodes were sometimes preceded by periods of insomnia progressing to agitation and violent outbursts. On one occasion, she banged her head against the wall and sustained a head injury that later required staples for wound closure. Her outbursts at times necessitated the use of 4-point restraints temporarily until the symptoms subsided and she was advised to wear protective headgear during these events for her safety. The head-banging incident prompted a reevaluation of her medication. Examination of her medications dosage over the several months revealed that on average, the clonazepam dosage was at about $11 \mathrm{mg}$ per day, eszopiclone $2 \mathrm{mg}$ PO QHS, and zolpidem tartrate $6.25 \mathrm{mg}$ QHS, and PHT 450mg every day, without relief of symptoms. The patient was placed on a mood stabilizer, and her clonazepam dosage was tapered down in parallel. The clonazepam was gradually decreased to 8mgwithout any adverse events. She was then placed on oxcarbazepine (Trileptal) $200 \mathrm{mg}$ PO BID as a mood stabilizer. However, within a week of being on the new medication, she developed confusion, dizziness, and an unsteady gait - signs of PHT toxicity. Subsequent tests revealed PHT blood levels to be $34.7 \mathrm{mcg} / \mathrm{mL}$ (Figure 1 ). Her oxcarbazepine was decreased to $150 \mathrm{mg}$ oral twice, daily and eventually discontinued altogether, along with her eszopiclone. Neurology was consulted again to evaluate the possible causes of her unsteady gait; phenytoin dosage was adjusted, her PHT level had fallen to $30.8 \mathrm{mcg} / \mathrm{mL}$. Eventually, the levels were normalized to $12.1 \mathrm{mcg} / \mathrm{mL}$.
I. Norethindrone/Ethinyl estradiol started
II. PHT stopped
III. First seizure in 6 months 


\section{Isoniazid started}

\section{Oxcarbazepine started}

\section{Discussion}

Phenytoin (5,5-diphenyl-2,4 imidazolidinedione), which was first synthesized in 1908, was the result of the search for a nonsedative Phenobarbital-like compound. Its anti-seizure property was not recognized until 1938 [7]. PHT is the oldest and moststudied non-sedating antiepileptic drug, but it remains unclear whether it acts as a single site or whether it affects many cellular processes [8]. It is known that PHT alters $\mathrm{Na}+\mathrm{K}+$, and $\mathrm{Ca}++$ conductance affects different neurotransmitters [9], and might also act by some other regulatory mechanisms [8]. It appears that PHT reduces or eliminates high-frequency firing neurons in a voltage-, usage-, and time-dependent manner [10]. Phenytoin is a weak organic acid that is poorly soluble in water. It is used either in acidic form or as salt with sodium equal to $98 \%$ of acidic form $[8,11]$. The acidic forms are Dilantin oral suspension of $30 \mathrm{mg}$ or $125 \mathrm{mg}$ PHT acid per $5 \mathrm{~mL}$ or chewable tablets of $50 \mathrm{mg}$ PHT acid [8]. The salt form with sodium are Dilantin Sodium Kapseals containing $30 \mathrm{mg}$ or $100 \mathrm{mg}$ or PHT sodium salt equivalent to $27.6 \mathrm{mg}$ and $92.0 \mathrm{mg}$ of PHT acid respectively; $100 \mathrm{mg}$ Mylan extended release form; or injectable forms $50 \mathrm{mg}$ PHT Sodium equal to $46 \mathrm{mg}$ of PHT acid in each $\mathrm{mL}$ [8].

Oral bioavailability of PHT is almost complete, but peak concentration after oral administration may range from 3-12 hours [11]. Plasma concentration after intramuscular injection is unpredictable, so this delivery is not recommended. (Phosphate salt of PHT, Phosphenytoin, on the other hand, is available intramuscularly [9]. After absorption, more than 90\% of PHT is bound to plasma protein, mainly albumin. Since only $10 \%$ of the drug is unbound, a small variation in protein-bound PHT can cause signification changes in free plasma levels [9]. Some drugs such as valproic acid (VPA) compete with PHT for plasma protein, affecting free plasma PHT levels [12]. Therefore, when used in combination with valproic acid, it is important to know the unbound portion of PHT rather than the total concentration in the plasma. In that particular poly-pharmacy, free PHT can be calculated unbiased and precisely from total plasma PHT levels and valproic acid levels using the following formula [8,12]:

$$
\text { Free PHT }=(0.095+0.001 \mathrm{mcg} / \mathrm{ml} *[V P A] *[\text { total PHT }])
$$

Less than $5 \%$ of PHT is excreted unchanged in the urine while over $95 \%$ is metabolized by liver cytochromeP450s (CYPs) before excretion [12]. PHT is mainly (90\%) metabolized by CYP 2C9 and to a lesser extent by CYP 2C19. It is predominantly converted to 5-(4-hydroxyphenyl)-5-phenylhydantoin (4'$\mathrm{HPPH}$ ), and a lesser extent (7-11\%) is metabolized to dihydrodiol [8]. Most of 4'-HPPH is excreted in urine in conjugation with glucuronide [13]. PHT is mostly metabolized via two liver cytochrome P450 enzymes; CYP 2C9 and CYP2C19. About 1000 different CYPs are known; about 50 of which are functionally active in humans [14]. Among them, CYP 3A4/5 metabolizes close to $60 \%$ of prescribed medications while CYP 2C family metabolizes about 16 commonly used drugs including PHT and war far in $[8,9,14]$. Four allelic variations of CYP2C9 have been identified; CYP2C $9 * 3$ has the lowest metabolizing activity $[7,10]$. Therefore, CYP2C9*3 is the primary determinant of slow PHT metabolism, but at higher doses variation in CYP2C19 becomes important [8]. The dosage at which the steady-state therapeutic level of $10-20 \mathrm{mcg} / \mathrm{mL}$ is reached differs in each. It depends on CYP2C9 and CYP2C19 variations and dose-dependent change in the pharmacokinetics of PHT. Below $10 \mathrm{mcg} / \mathrm{mL}$, PHT metabolism follows first pass (linear) while at therapeutic levels, $10-20 \mathrm{mcg} /$ $\mathrm{mL}$, the drug follows zero order (non-linear) metabolism $[8,15]$. PHT has extensive drug-drug interactions; the pharmacokinetics of PHT is altered by other medications, and PHT, in turn, affects the metabolism of other medicines [8]. Some drugs increase PHT level (e.g., chlordiazepoxide, oxcarbazepine, topiramate, valproic acid, salicylates, fluoxetine, fluvoxamine, imipramine, sertraline, trazodone, isoniazid); others decrease the level (clonazepam, vigabatrin, rifampin), while some may have a variable effect (carbamazepine, diazepam) $[5,11]$ (Table 1).

Table 1: Phenytoin Drug Interaction Table.

\begin{tabular}{|c|c|c|}
\hline Drugs Increase Phenytoin Serum Level & Drugs Decrease Phenytoin Serum Level & $\begin{array}{c}\text { Drugs That May Either Increase } \\
\text { Or Decrease Phenytoin Serum } \\
\text { Level }\end{array}$ \\
\hline $\begin{array}{l}\text { Acute alcohol intake, amiodarone, anti-epileptic agents } \\
\text { (ethosuximide, felbamate, oxcarbazepine, methsuximide, } \\
\text { topiramate), azoles (fluconazole, ketoconazole, itraconazole, } \\
\text { miconazole, voriconazole), capecitabine, chloramphenicol, } \\
\text { chlordiazepoxide, cimetidine, disulfiram, estrogens, fluorouracil, } \\
\text { fluoxetine, fluvastatin, fluvoxamine, H2-antagonists (e.g. } \\
\text { cimetidine), halothane, isoniazid, methylphenidate, omeprazole, } \\
\text { phenothiazines, salicylates, sertraline, succinimides, sulfonamides } \\
\text { (e.g., sulfamethizole, sulfamethoxazole-trimethoprim), ticlopidine, } \\
\text { tolbutamide, trazodone, and Warfarin }\end{array}$ & $\begin{array}{l}\text { Anticancer drugs usually in } \\
\text { combination (e.g., bleomycin, } \\
\text { carboplatin, cisplatin, doxorubicin, } \\
\text { methotrexate), carbamazepine, chronic } \\
\text { alcohol abuse, diazepam, diazoxide, } \\
\text { folic acid, fosamprenavir, nelfinavir, } \\
\text { reserpine, rifampin, ritonavir, St. John's } \\
\text { Wort, theophylline, and vigabatrin }\end{array}$ & $\begin{array}{l}\text { Phenobarbital, sodium } \\
\text { valproate, and valproic acid. } \\
\text { Similarly, the effect of phenytoin } \\
\text { on phenobarbital, valproic acid, } \\
\text { and sodium valproate serum } \\
\text { levels is unpredictable. }\end{array}$ \\
\hline
\end{tabular}






Figure 2: PHT pharmacokinetic changes from linear to nonlinear pattern at therapeutic [15].

The unusual pharmacokinetics of PHT should be taken into consideration when adjusting the dosage. It has been observed that PHT clearance varies inversely with its plasma concentration, whereas its half-life changes directly with the plasma concentration [8]. In other words, at therapeutic levels, elimination of PHT is decreased while its half-life is increased, creating a vicious cycle- as plasma PHT levels rise, its half-life increases and its elimination decreases. These events result in further elevation of plasma concentration and the cycle continues, resulting in rapid toxicity. At steady-state, increases or decreases in the dosage of PHT solely based on linear extrapolation of drug levels result in unexpectedly high or low plasma concentrations $[8,16]$. Small changes in the dosage of medication may lead to considerable alteration in the plasma concentration of the drug (Figure 2). It should be noted that the commonly accepted half-life of 24 hours only applies at the lower therapeutic levels of PHT (approx. $10 \mathrm{mcg} / \mathrm{mL}$ ). The elimination half-life of PHT at $40 \mathrm{mcg} / \mathrm{mL}$ has been reported between 37.1 to 96 hours [9]. Therefore, it may take 4 to 6 weeks for steady-state plasma concentration to stabilize.

The unusual pharmacokinetics of PHT should be taken into consideration when adjusting the dosage. It has been observed that PHT clearance varies inversely with its plasma concentration, whereas its half-life changes directly with the plasma concentration [8]. In other words, at therapeutic levels, elimination of PHT is decreased while its half-life is increased, creating a vicious cycle- as plasma PHT levels rise, its half-life increases and its elimination decreases. These events result in further elevation of plasma concentration and the cycle continues, resulting in rapid toxicity. At steady-state, increases or decreases in the dosage of PHT solely based on linear extrapolation of drug levels result in unexpectedly high or low plasma concentrations $[8,16]$. Small changes in the dosage of medication may lead to considerable alteration in the plasma concentration of the drug (Figure 2). It should be noted that the commonly accepted half-life of 24 hours only applies at the lower therapeutic levels of PHT (approx. $10 \mathrm{mcg} / \mathrm{mL}$ ). The elimination half-life of PHT at $40 \mathrm{mcg} / \mathrm{mL}$ has been reported between 37.1 to 96 hours [9]. Therefore, it may take 4 to 6 weeks for steady-state plasma concentration to stabilize.
Because of these changes in half-life and elimination of the drug at higher plasma levels, the time required for PHT to fall to a therapeutic range from a toxic level is unpredictable [17]. Therefore, at toxic levels, PHT should be withheld, and daily levels should be drawn until the drug levels fall in the therapeutic range. A useful method for adjusting PHT dosage based on its level is that the dosage of the drug can be changed by $100 \mathrm{mg}$ daily if the plasma level is between $5-10 \mathrm{mcg} / \mathrm{mL}$ and by $30-50 \mathrm{mg}$ when the plasma level is over ten $\mathrm{mcg} / \mathrm{mL}$ [8]. If PHT is being prescribed for the first time, it could be ordered as $100 \mathrm{mg}$ orally three times a day, and PHT levels should be drawn daily to determine dosage adjustments [9]. While prescribing PHT, other conditions that might result in a change in its metabolism should also be considered. For instance, decreased plasma albumin after a head trauma that may take up to 4 weeks to normalize may result in increased free PHT levels, requiring a frequent adjustment in PHT dosage [8]. Likewise, an elevated amount of free PHT is also observed in neonates and patients with uremia [9]. On the contrary, increased metabolism of the drug during pregnancy lowers the steady-state concentration of PHT in pregnant women [17]. Similarly, in children, the clearance of PHT is higher, and its elimination half-life is shorter, requiring higher average dosing rates $(\mathrm{mg} / \mathrm{Kg}$ ) [8]. Such unusual conditions should also be taken into account when prescribing PHT for seizure disorders.

\section{Conclusion}

Understanding the pharmacokinetics of PHT will improve care for psychiatric patients. Besides the drug-drug interaction, PHT requires particular attention due to its unique pharmacokinetic properties. The circumstances leading to this case could have been avoided the unusual nature of PHT been taken into consideration. Rapid adjustments in the dosage of PHT during periods of toxicity predisposed the patient to subtherapeutic PHT levels that were below the standard range. Thus the patient ends up with a seizure after a 6-month seizurefree period. Additionally, given that other medications were necessary for the treatment of her co-morbidities, not adequately adjusting the dosage of PHT when adding other drugs to the regimen resulted in PHT toxicity. Since psychiatric patients may fail to follow up with generalists or specialists and noncompliance with prescribed meds is not uncommon among this patient population therefore [17], psychiatrists and psychiatric residents should be familiar with adjusting non-psychiatric medications including antiepileptic medications such as PHT. This comprehensive review the complex pharmacokinetic property of PHT may enhance patients' care and quality of life and reduces the incidence of adverse side effects caused by drug-drug interaction.

\section{References}

1. Hauser WA, Hesdorffer DC (1990) Epilepsy-frequency, causes, and consequences. Demos Medical Publishing, New York, USA, p. 1-51.

2. Gaitatzis A, Trimble MR, Sander JW (2004) The psychiatric comorbidity of epilepsy. Acta Neurol Scand 110(4): 207-220. 
3. Rosati A, De Masi S, Guerrini R (2015) Antiepileptic Drug Treatment in Children with Epilepsy. CNS Drugs 29(10): 847-863.

4. Mamiya K, Ieiri I, Shimamoto J, Yukawa E, Imai J, et al. (1998) The Effects of Genetic Polymorphisms of CYP2C9 and CYP2C 19 on Phenytoin Metabolism in Japanese Adult Patients with Epilepsy: Studies in Stereoselective Hydroxylation and Population Pharmacokinetics. Epilepsia 39(12): 1317-1323.

5. Nation RL, Evans AM, Milne RW (1990) Pharmacokinetic drug interactions with phenytoin (Part I). Clin Pharmacokinet 18(1): 3760 .

6. St Louis EK (2009) Monitoring Antiepileptic Drugs: A Level-Headed Approach. Current Neuropharmacology 7(2): 115-119.

7. A Ashnagar N, Gharib Naseri, M Amini (2009) Synthesis of 5,5-Diphenyl-2,4-imidazolidinedione (Phenytoin) from Almond. Asian Journal of Chemistry 21(7): 4976-4980.

8. Levey RH, Richard HM, Brian SM, Emilio Perucca (2002) Antiepileptic Drugs. (5 ${ }^{\text {th }}$ edn.). Lippincott Williams \& Wilkins, Philadelphia, USA.

9. Katzung BG (2001) Basic and Clinical Pharmacology ( $8^{\text {th }}$ edn.). Lange Medical, New York, USA.

10. Bazil CW, Pedley TA (1998) Advances in the Medical Treatment of Epilepsy. Annu Rev Med 49: 135-162.

11. Chiang PC, Wong H (2013) Incorporation of Physiologically
Based Pharmacokinetic Modeling in the Evaluation of Solubility Requirements for the Salt Selection Process: A Case Study Using Phenytoin. The AAPS Journal 15(4): 1109-1118.

12. Kerrick JM, Wolff DL, Graves NM (1995) Predicting Unbound Phenytoin Concentration in Patients Receiving Valproic Acid: a Comparison of Two Predictions Methods. Ann-Pharmacother 29(5): 470-474.

13. Yamanaka H, Nakajima M, Hara Y, Katoh M, Taachibana O, et al. (2005) Urinary Excretion of Phenytoin Metabolites, 5-(4'-hydroxyphenyl)-5Diphenylhydantoin and its O-Glucuronide in Humans and Analysis of Genetic Polymorphisms of UDP-glucuronosyltransferases. Drug Metab Pharmacokinet 20 (2): 135-143.

14. Hardman JG, Limbird LL (2001) The Pharmacological Basis of Therapeutics $\left(10^{\text {th }}\right.$ edn.). McGraw-Hill, New York, USA.

15. Marwer GE, Mullen PW, Rogers M, AJ Robins, SB Lucas (1974) PHT Dose Adjustment in Epileptic Patients. Br J Clin Pharma 1: 163-168.

16. Reynolds EH (1975) The Value of Serum Diphenylhydantoin (PHT) Levels in the Management of Epilepsy. Proc Roy Soc Med 68(2): 102 $-104$.

17. Dickinson RG, WD Hooper, B Wood, CM Lander, MJ Eadie (1989) The Effect of Pregnancy in Humans on the Pharmacokinetics of Stable Isotope Labelled Phenytion. Br J Clin Pharma 28(1): 17-27.

\section{Your next submission with Juniper Publishers will reach you the below assets}

- Quality Editorial service

- Swift Peer Review

- Reprints availability

- E-prints Service

- Manuscript Podcast for convenient understanding

- Global attainment for your research

- Manuscript accessibility in different formats ( Pdf, E-pub, Full Text, Audio)

- Unceasing customer service

Track the below URL for one-step submission

https://juniperpublishers.com/online-submission.php 